NBER WORKING PAPER SERIES

LOAN COMMITMENTS AND

OPTIMAL MONETARY POLICY

Michael Woodford

NBER Working Paper 5660

NATIONAL BUREAU OF ECONOMIC RESEARCH

1050 Massachusetts Avenue

Cambridge, MA 02138

July 1996

Previously circulated under the title "Optimal Monetary Policy in an Economy with Sequential Service." The ideas developed here have been considerably refined through years of discussion with Ben Eden and Bob Lucas, neither of whom, however, can be held responsible for the form they have ultimately taken. I would also like to thank Dennis Carlton, Peter Diamond, Mark Gertler, Donald Morgan, Julio Rotemberg, Alberto Trejos, Steve Williamson and an anonymous referee for helpful comments, the Institut d'Anàlisi Econòmica (Barcelona) for its hospitality while I wrote the first draft of this paper, and the NSF for research support. This paper is part of NBER's research program in Monetary Economics. Any opinions expressed are those of the author and not those of the National Bureau of Economic Research.

(C) 1996 by Michael Woodford. All rights reserved. Short sections of text, not to exceed two paragraphs, may be quoted without explicit permission provided that full credit, including $\odot$ notice, is given to the source. 


\title{
LOAN COMMITMENTS AND \\ OPTIMAL MONETARY POLICY
}

\begin{abstract}
With loan commitments negotiated in advance, the use of "tight money" to restrain nominal spending has asymmetric effects upon different categories of borrowers. This can reduce efficiency, even though aggregate demand is stabilized. This is illustrated in the context of an equilibrium model of financial intermediation with loan commitments, where monetary policy is characterized by a supply curve for reserves on the part of the central bank in an inter-bank market.

If demand uncertainty relates primarily to the intensity of demand by each borrower with no difference in the degree of cyclicality of individual borrowers' demands, an inelastic supply of reserves by the central bank is optimal, because it stabilizes aggregate demand and as a result increases average capacity utilization. But if demand uncertainty relates primarily to the number of borrowers rather than to each one's demand for credit, an interest-rate smoothing policy is optimal, because it eliminates inefficient rationing of credit in high-demand states.
\end{abstract}

\author{
Michael Woodford \\ Department of Economics \\ Princeton University \\ Princeton, NJ 08544 \\ and NBER
}


In Robert Lucas's celebrated analysis, unexpected variations in the money supply affect economic activity because the suppliers of goods have incomplete information about the current state of aggregate demand. In Lucas (1972), information is imperfect because of the segmentation of goods markets and the existence of shocks to relative as well as aggregate demand. In the related analysis of Lucas and Woodford (1994), information is imperfect because retail markets for goods are not Walrasian auction markets, but instead involve sequential trade. Both models imply that monetary instability reduces the efficiency of the allocation of resources, by impairing the ability of market prices to induce efficient supply decisions in a decentralized economy.

Such analyses clearly show that the creation of uncertainty about the level of nominal aggregate demand as a result of random actions by the central bank is undesirable. They fail, however, to show whether it is desirable for a central bank to adopt operating procedures that imply variation in the money supply in response to shocks originating elsewhere in the economy. In particular, they leave open the question whether, in the face of real shocks that cause variations in the demand for bank credit, it is better to keep the money supply constant, at the cost of sharp, unexpected variations in interest rates, or better to accommodate such shocks, allowing the money supply and bank credit to vary in order to smooth interest rates. This question is one of considerable practical importance, given the centrality of interestrate smoothing among the objectives of actual central banks, ${ }^{1}$ and given the fact that current operating procedures for monetary policy in the United States and elsewhere typically involve short-run control of a short-term nominal interest rate (such as the Federal Funds rate in the U.S.), rather than a monetary aggregate. ${ }^{2}$ The present paper focuses upon this particular aspect of monetary policy, because it is not necessary to assume that the central bank changes its policy stance in response to any information about current shocks that is not possessed by private parties and incorporated into their pricing policies; rather, one may consider the nature of the optimal supply schedule for reserves on the part of the central bank, given what this implies about the automatic variations of the money supply in response to shocks that will result from such an operating procedure.

A familiar answer to this question is that of Poole (1970): short-run interestrate stabilization is desirable if the main source of disturbances is in the demand for money balances given a particular level of transactions ("LM shocks"), since it prevents such disturbances from affecting aggregate demand in the goods market, but is undesirable if the main source of disturbances is in the real determinants of aggregate demand for a given level of interest rates ("IS shocks"), since in that case the interest-rate smoothing results in greater instability of aggregate demand. This paper shows, instead, that there may be advantages to interest-rate smoothing even when the relation between desired spending and desired transactions balances is completely stable (and indeed, the velocity of money is constant). ${ }^{3}$ The reason is

\footnotetext{
${ }^{1}$ See, e.g., Miron (1986), Goodfriend (1991), and Meltzer (1995).

${ }^{2}$ See, e.g., Taylor (1993), and Clarida and Gertler (1995).

${ }^{3}$ The point here is not to deny the importance of stochastic disturbances to money demand in
} 
not that Poole's analysis is wrong; in the model presented here, a more elastic supply of reserves by the central bank does result in greater volatility of aggregate demand, and as a result both greater instability of aggregate output and a lower average level of capacity utilization. However, this need not imply a lower level of welfare, when the allocation of the national product across alternative uses is considered; and it is here that a simple IS-LM analysis is most inadequate.

The problem with using "tight money" as a way of restraining surges in aggregate demand due to real causes is that the existence of loan commitments insulates many firms from the effects of any such tightening, so that the growth of bank lending is restrained only through a disproportionate effect upon the supply of credit to certain categories of borrowers, that have not obtained such commitments in advance. 4 As a result, a policy of tightly controlling the money supply will not only stabilize aggregate output, but will imply that a greater proportion of available output during high-demand periods will be purchased by certain types of buyers (in practice, larger, more stable firms) rather than others (smaller, riskier firms), ${ }^{5}$ which need not improve overall welfare.

The present paper addresses these issues in the context of an explicit equilibrium model of the effects of monetary policy upon financial intermediation. Fluctuations in the volume of nominal spending affect the degree of utilization of productive capacity, because transactions in the goods market are subject to a sequential service constraint, as a result of which supply commitments made to individual buyers cannot be contingent upon the overall state of demand. The intention is to model equilibrium in a goods market where goods are allocated through non-price rationing, as seems to be true in many actual markets, due to the prohibitive informational requirements for the organization of a competitive auction market. ${ }^{6}$ This feature of the model creates a reason for the control of nominal aggregate demand to matter.

It is assumed that purchases can only be made using cash borrowed from banks, in order to create a straightforward link between the volume of bank lending and aggregate demand. ${ }^{7}$ Stochastic variations in the desired level of level of purchases (absent any change in supply or credit market conditions) occur as a result of random shocks to household preferences; these shocks are allowed to shift not just the average intensity of demand for current consumption, but the distribution of demand across

practice, but to show that the question of the optimal response to pure "IS shocks" is a more subtle one than is commonly appreciated.

${ }^{4}$ This argument was first made by Wojnilower (1980).

${ }^{5}$ Morgan (1992) shows that the volume of lending under commitments does not significantly decline after a deliberate tightening of monetary policy, while loans not under commitment do promptly decline, and argues that the share of loans not under commitments is a useful indicator of the stance of monetary policy.

${ }^{6}$ See Carlton (1991) for further discussion; on the relevance of this for the explanation of nominal price rigidity, see Lucas and Woodford (1994) and Diamond (1994). The model of the goods market used here is closely related to that of Lucas and Woodford; see the end of section 2.1 for discussion of the differences.

${ }^{7}$ This is an oversimplification, but such a "credit channel" is often argued to play an important role in the transmission mechanism for monetary policy (e.g., Bernanke and Gertler, 1995). 
different types of consumers as well. ${ }^{8}$ Monetary policy is modelled in terms of the central bank's supply of funds to an interbank market, in which commercial banks finance their lending activity. The optimal policy issue considered concerns the degree to which the money supply (and, in this model, the volume of bank lending) should be allowed to vary endogenously in response to the preference shocks, due to the nature of the central bank's supply of funds to the interbank market.

The consumer credit market is assumed to be subject to a sequential service constraint, just as in the case of the goods market. This means that banks enter into loan supply commitments in advance, that cannot be made contingent upon the overall state of credit demand. In the model, all loans are made under commitments, just as all sales of goods are; but borrowers' differing ex ante characteristics determine whether they obtain more or less favorable terms. Borrowers who are expected to borrow only at times of high demand cannot obtain commitments that entitle them to borrow at a low rate of interest, and it is in this sense that the favorable commitments obtained by the other borrowers result in these borrowers' bearing the brunt of the "credit crunch". The existence of commitments with these differential terms is shown to be an equilibrium phenomenon, in the case of a central bank policy that seeks to restrain money growth during times of high demand. On the other hand, a central bank commitment to interest-rate smoothing (an elastic supply of funds) results in all borrowers obtaining loan commitments on similar terms. Under a certain extreme specification of the nature of the exogenous uncertainty in the economy, a perfectly elastic supply of funds can be shown to be optimal.

The paper proceeds as follows. Section 1 gives an overview of the structure of the model. Section 2 then derives the conditions that characterize the stationary equilibrium associated with a given monetary policy. Finally, section 3 discusses the welfare properties of the equilibria associated with alternative policies, and section 4 concludes.

\section{An Equilibrium Model of Goods and Loan Sup- ply Commitments}

In this section, we describe the structure of the model. The economy consists of four types of agents: households, firms, commercial banks, and a government that operates a central bank. (The numbers of households and firms are each normalized to one.) The households negotiate goods supply commitments with the firms and loan supply commitments with the commercial banks. After a random shock is realized that determines the current state of aggregate demand, they exercise these commitments to some degree, borrowing money from the banks and using it to purchase goods from the firms. The funds that the banks lend out are obtained from deposits from households,

\footnotetext{
${ }^{8}$ It would be more realistic to consider differing degrees of volatility in the investment spending of different types of firms, but the model is simplified by abstracting from investment and endogenous productive capacity altogether.
} 
and in an interbank funds market, in which the central bank also participates. The monetary policy question addressed in the paper concerns the rule to be followed in the central bank's supply of funds in this interbank market.

Households are all identical, but each household is made up of a large number of individual members, each of whom obtains utility from his or her own purchases of goods. The tastes of the different members of a household differ, and in particular, are differently affected by the aggregate state. The members also act independently during each period, each negotiating individual goods and loan supply commitments, and making individual decisions to borrow and to purchase goods under those commitments. However, at the end of each period, the separate household members merge their assets and obligations in a single household budget, and it is only the budget constraint of the household as a whole that is ultimately binding. It is assumed that households can in some way induce their members to act so as to maximize a common objective (average utility of all of the members) subject to the common budget constraint. This device is introduced (following Lucas, 1990, and Fuerst, 1992) in order to allow us to retain the simplicity of a representative-household analysis (i.e., to avoid having to model the evolution of a wealth distribution) while nonetheless allowing shocks to have asymmetric effects. The same result might equivalently be obtained (at the expense of additional notation) by allowing atomistic individuals to insure one another, before learning their "types", against the (fully diversifiable) risk of turning out to be a type that is especially adversely affected in a given state of the economy. ${ }^{9}$

The objective of each household is thus to maximize

$$
E\left\{\sum_{t=0}^{\infty} \beta^{t} \sum_{i} n_{i} \delta_{i}\left(s_{t}\right) u\left(c_{t}^{i}\right)\right\}
$$

where $c_{t}^{i}$ denotes the consumption per member of type $i$ in period $t$. Here $n_{i}>0$ is the fraction of members that are of type $i$, and $\delta_{i}\left(s_{t}\right)>0$ is a time-varying preference shock that is type-specific; the state of aggregate demand $s_{t}$ in period $t$ determines each person's current intensity of utility from consumption, but may affect different types differentially. (In particular, some types may have more cyclical variation in their desire to consume than others.) The expectation is over possible histories of realizations of the states $\left\{s_{t}\right\}$. I assume, for simplicity, that $s_{t}$ is independently drawn each period from the same finite set $S \equiv\{1,2, \ldots, \bar{s}\}$; the probability $\pi_{s}$ of a given state $s$ occurring is the same each period. I assume that states are ordered so that for each type $i, s^{\prime} \geq s$ implies that $\delta_{i}\left(s^{\prime}\right) \geq \delta_{i}(s)$. This implies that larger values of $s$ correspond unambiguously to higher levels of demand for current consumption. Finally, $0<\beta<1$ is a constant discount factor, and $u(\cdot)$ is a strictly increasing, strictly concave, continuously differentiable function, defined for all non-negative levels of consumption.

\footnotetext{
${ }^{9}$ This was shown in the conference draft of this paper, available from the author upon request.
} 


\subsection{Sequential Trade}

The sequence of events during any given period is as follows. Each household begins the period with nominal wealth in the form of deposits worth $D \geq 0$ with one or another of the banks. ${ }^{10}$ Competition among the banks for these deposits determines a market-clearing gross nominal interest rate $r^{d}$ for these deposits, payable at the end of the period. Banks begin with assets and liabilities that consist solely of the funds $D$ deposited with them by the households. Firms begin with a productive capacity of $y>0$ units of a homogeneous, non-durable good. Firms begin the period with no other assets, as they distribute their earnings to the households that own them at the end of each period.

Exchange is assumed to occur each period in two stages. In a first stage, household members negotiate supply commitments with firms, that are then executed during the second stage. Simultaneously, household members negotiate loan commitments with commercial banks. In these negotiations, individual household members each negotiate their own supply commitments, with the type of each person being public information, but with neither party yet knowing the state of aggregate demand $s$. Prior to the execution stage, the state $s$ is revealed to buyers, but not to sellers. Household members then decide to what extent to borrow funds under their loan commitments, and to what extent to purchase goods under their supply commitments. Each household member's demand for the good in the execution stage depends upon the aggregate state $s$, insofar as its utility from consumption in the current period is given by $\delta_{i}(s) u(c)$. The realization of this shock also determines the degree to which loan commitments are exercised, as the household members require cash loans in order to be able to pay cash for the goods that they purchase. ${ }^{11}$

The significance of the negotiation stage is that it is assumed that at this stage, buyers and sellers are able to costlessly negotiate supply contracts in a competitive environment with full information. On the other hand, once the state $s$ is realized, it is assumed not to be possible to organize a centralized Walrasian spot market for the good. Instead, suppliers must be able to fill orders placed by individual buyers without waiting to learn the state of aggregate demand $s$. This is the sequential service constraint referred to above. ${ }^{12}$

Suppliers negotiate in advance the terms under which they will supply goods to particular buyers, should these buyers present them with orders during the execution stage. But the supply commitment made to an individual buyer cannot be contingent

\footnotetext{
${ }^{10}$ I drop the time subscript in the following discussion, as no ambiguity should be created. Note that in the stationary equilibrium that is characterized below, quantities such as $D$ take the same value in every period.

${ }^{11}$ Household members do not have access to the household's deposits with the banks in order to satisfy the cash-in-advance constraint on their purchases; for interest is paid on these time deposits exactly because the bank is able to use them to make cash loans to household members who choose to draw down their loan commitments.

${ }^{12}$ The terminology follows Diamond and Dybvig (1983), who assume a constraint of this kind on the form of commitment that a financial intermediary can make with its depositors regarding the terms of withdrawal.
} 
upon the purchases made by any other buyers, and so cannot be contingent upon the aggregate state $s$. The existence of the negotiation stage makes it possible for types that are more certain of their desire for the good to negotiate a secure supply of the good on favorable terms (which sellers will grant them, on the basis of their type, in order to reduce the risk of ending with unused capacity). ${ }^{13}$ However, since the state of demand is not known to sellers, buyers do not have an enforceable obligation to buy any amount. Rather, a seller is committed to supply any amount demanded by the buyer, up to a certain quantity limit, at a prearranged price schedule, that may make the supply price depend upon the quantity that the buyer purchases. The actual quantity purchased under this commitment, $c_{i}(s)$, remains at the discretion of the buyer, and will in general depend upon the realization of the state $s$. Thus sellers are not able to "sell forward" their output in the negotiation stage, and unused capacity is possible in equilibrium.

Finally, it is assumed that the supply commitments must indicate the price (if any) at which each successive additional purchase by a buyer can be made, simply as a function of the number of units already purchased by that buyer, and not contingent upon the eventual quantity that the buyer might subsequently purchase. This is another aspect of the sequential service constraint.

Thus a supply commitment for a buyer of type $i$ takes the form of a quantity limit $\bar{c}_{i}$ and a right-continuous function $p_{i}(\cdot)$ defined on the interval $\left[0, \bar{c}_{i}\right)$. Here $p_{i}(c)$ denotes the price at which the next increment of the good is available to the buyer, after a quantity $c$ has already been purchased. (The assumption of right-continuity means that if $p_{i}(c)=p$, it is possible for some additional positive quantity of the good to be purchased at an average price that is arbitrarily close to $p$; in the absence of this, it would not be meaningful to say that further purchases are possible at the price $p$. Treating purchases as a continuous variable simplifies the analysis of competitive equilibrium, as usual.) Allowing $p_{i}$ to depend upon the quantity purchased makes it possible for sellers to raise their prices to some extent in high-demand states, but in a way that respects the sequential service constraint. Under such a commitment, a buyer who decides to purchase a quantity $c$ must pay $R_{i}(c)$, where

$$
R_{i}(c) \equiv \int_{0}^{c} \dot{p}_{i}\left(c^{\prime}\right) d c^{\prime}
$$

Firms are assumed to be able to extend only supply commitments that they are able to fulfill. Since the commitment to any one buyer cannot be contingent upon whether other buyers choose to execute their commitments, this means that the total number of units of output that a given firm commits itself to supply may not exceed its productive capacity $y$. This implies an aggregate feasibility condition of the form

$$
\sum_{i} n_{i} \bar{c}_{i} \leq y
$$

\footnotetext{
${ }^{13}$ Carlton (1991) gives examples of markets in which customers pay more the greater the correlation between their individual demand and the firm's aggregate demand. Such a relationship is predicted by the model developed here.
} 
The consumer credit market, like the goods market, is assumed to be subject to a sequential service constraint. This means that during the negotiation stage, household members also negotiate loan commitments, specified by a quantity limit $\vec{M}_{i}$ and a supply function $r_{i}(\cdot)$, indicating the terms upon which that buyer can borrow. Here $\bar{M}_{i}$ is the maximum quantity that may be borrowed during the execution stage, and $r_{i}(M)$ indicates the interest rate at which the next incremental loan is available, after a quantity $M$ has already been borrowed. As before, $r_{i}(\cdot)$ is assumed to be a rightcontinuous function defined on the interval $\left[0, \bar{M}_{i}\right)$. The quantity $r_{i}(M)$ is a gross nominal interest rate on loans of cash, so that if the quantity borrowed is $M$, the repayment obligation due at the end of the period is given by $B_{i}(M)$, where

$$
B_{i}(M) \equiv \int_{0}^{M} r_{i}\left(M^{\prime}\right) d M^{\prime}
$$

In the execution stage, each household member decides what quantity of goods to purchase and what quantity of money to borrow, given the state $s$ that has been realized. The purchases $c_{i}(s)$ and borrowing $M_{i}(s)$ of a buyer of type $i$ must satisfy the cash-in-advance constraint

$$
R_{i}\left(c_{i}(s)\right) \leq M_{i}(s)
$$

These decisions result in aggregate consumption (and capacity utilization) $c(s) \equiv$ $\sum_{i} n_{i} c_{i}(s)$, aggregate nominal expenditure $Y(s) \equiv \sum_{i} n_{i} R_{i}\left(c_{i}(s)\right)$, aggregate borrowing (and transactions balances) $M(s) \equiv \sum_{i} n_{i} M_{i}(s)$, and aggregate repayment obligations to the banks $B(s) \equiv \sum_{i} n_{i} B_{i}\left(M_{i}(s)\right)$.

During the execution stage, firms supply the goods that are demanded, using their productive capacity. Banks supply the money that household members choose to borrow, obtaining any necessary funds in excess of the deposits that households have made with them in a competitive interbank funds market (in which banks with excess deposits may also lend them out). This market is assumed to be held only after the execution stage is complete, so that banks have learned their need for funds to satisfy the transactions needs of their borrowers. We may suppose that during the execution phase itself, the banks obtain the cash needed by drawing upon reserves that they maintain with the central bank. After the execution phase is completed, however, they are required to replenish these reserves, through the interbank funds market. (The central bank requires them to hold a certain quantity of reserves, as of the end of this interbank trading, but prior to repayment of the households' loans.) This market is a competitive spot market, assumed to involve no sequential service constraint, as only specialists - the commercial banks and the central bank participate in it. The interbank funds market clears at an interest rate $\rho(s)$, that may depend upon the state of aggregate demand (as may banks' need for funds). Because the funds market is cleared only after completion of the execution phase, this interest rate does not reveal the state of aggregate demand soon enough for goods or loan supply commitments to be made contingent upon it.

The fact that reserve requirements must be met (and the funds market clears) only after completion of the execution stage allows the central bank to vary the supply 
of funds to banks (and hence the supply of transactions balances) in different states of aggregate demand. The way in which it should do so is the question of monetary policy that we wish to analyze. Monetary policy is described by the central bank's supply schedule in the interbank funds market. This can be described by a funds supply correspondence $\Gamma$, indicating the pairs of interest rates $\rho$ and net supplies of funds $F$ to the commercial banks (net lending by the central bank) that are consistent with the central bank's policy. Market clearing in the interbank funds market then requires that $M(s)=D+F(s)$, and hence that

$$
(\rho(s), M(s)-D) \in \Gamma
$$

for each state $s$. The central bank is required to commit itself to a correspondence $\Gamma$ prior to realization of the state of aggregate demand, though the point on this correspondence that is actually reached as the equilibrium of the funds market may depend upon the realization of $s$. The reason for restricting attention to monetary policies of this form is to show that there can exist a non-trivial role for monetary policy even under the assumption that the central bank has no information about the state of the economy that is superior to that of any private parties. The central bank's policy problem then reduces to the question of whether to choose a more or less elastic funds supply correspondence.

Finally, all accounts are settled at the end of the period. Firms distribute their profits to the households, that own them; since the revenues of firms equal total expenditure on goods, the amount distributed to the representative household is simply $Y(s)$. Commercial banks pay households $r^{d} D$ for their deposits, and repay their loans from the central bank, in the amount of $\rho(s) F(s)$. At the same time, they receive payments of aggregate value $B(s)$ from their borrowers; the excess of this amount over their interest obligations represents profits that are distributed to the households, that own the banks as well. Thus total profits distributed (by firms and banks) per household at the end of the period are given by

$$
\Pi(s)=Y(s)+[B(s)-\rho(s) M(s)]+\left[\rho(s)-r^{d}\right] D .
$$

Individual household members merge their budgets, pooling any unspent cash $\left(M_{i}-\right.$ $R_{i}\left(c_{i}(s)\right.$ ) for each member of type $i$ ), and assigning to the household responsibility for their loan repayment obligations to the banks $\left(B_{i}\left(M_{i}(s)\right)\right.$ for each member of type $\left.i\right)$. The government makes net lump-sum transfers to each household in an amount $T(s)$, that may depend upon the aggregate state; these allow the government to rebate to the private sector the central bank's earnings from lending to the commercial banks. The household's nominal wealth (held in the form of bank deposits) at the beginning of the following period then equals

$$
D^{\prime}(s)=r^{d} D+\sum_{i} n_{i}\left[M_{i}(s)-R_{i}\left(c_{i}(s)\right)-B_{i}\left(M_{i}(s)\right)\right]+\Pi(s)+T(s),
$$

where $\Pi(s)$ is given by (1.7). A household is constrained to act so that $D^{\prime}(s) \geq 0$; thus all loans are in fact repaid at the end of the period. 
This completes our description of the sequence of events that take place each period. Trade proceeds in the next period in the same way, beginning with deposits $D^{\prime}$ of households with the commercial banks.

\subsection{Optimization and Equilibrium}

Now let the maximium attainable level of continuation utility attainable by a household that begins the next period with deposits $D^{\prime}$, in the case that the current aggregate state is $s$, be denoted $v\left(D^{\prime} ; s\right) .{ }^{14}$ Note that this function may, in general, be different in the case of different states $s$, because the equilibrium in the following period depends not only upon the wealth $D^{\prime}$ carried into the next period by this particular household, but also upon the wealth carried into the next period by others, which may depend upon the state $s .{ }^{15}$ It then follows that the actions $\left\{c_{i}(s), M_{i}(s)\right\}$ of the various household members during the execution stage are chosen, given the aggregate state $s$, so as to maximize

$$
\sum_{i} n_{i} \delta_{i}(s) u\left(c_{i}(s)\right)+\beta v\left(D^{\prime}(s) ; s\right),
$$

subject to constraint (1.5) for each type $i$, taking as given that $D^{\prime}(s)$ depends upon these decisions in the way indicated by (1.8), and the values of $\Pi(s)$ and $T(s)$.

At the negotiation stage, each firm $j$ enters into supply commitments that imply state-dependent sales revenues $R^{j}(s)$ that maximize the expected continuation utility of its shareholders,

$$
\sum_{s \in S} \pi_{s} v\left(D^{\prime}(s) ; s\right),
$$

subject to the feasibility constraint (that the total number of supply commitments not exceed its productive capacity $y$ ), taking as given that $D^{\prime}(s)$ depends upon the firm's profits in the way indicated by (1.8), and taking as given the state-dependent variation in all other terms in (1.8). Since an individual firm's revenues contribute only negligibly to shareholders' wealth, this amounts to maximization of

$$
\sum_{s \in S} \pi_{s} v^{\prime}\left(D^{\prime}(s) ; s\right) R^{j}(s)
$$

taking as given the value of $D^{\prime}(s)$ in each possible state. In choosing its supply commitments, the firm also takes as given the degree to which its customers will choose to exercise such commitments in each possible state $s$. These expectations

\footnotetext{
${ }^{14}$ Standard dynamic programming arguments can be used to show existence of such a value function, and that it is an increasing, concave function, differentiable at the level of wealth that is actually carried into the next period in equilibrium. The sort of argument that may be used is illustrated for a related model by Lucas and Woodford (1994).

${ }^{15}$ The exact way in which aggregate outcomes in the state $s$ determine the value of individual wealth in the following period need not be explicitly represented for present purposes, since individual households will in any event not be able to affect those aggregate outcomes, only the way that their own wealth $D^{\prime}$ varies with $s$.
} 
follow from a correct understanding of how household members will behave in order to maximize their objective (1.9), a matter treated in more detail in section 2.

Similarly, each bank $k$ enters into loan commitments that maximize the expected value of its profits to its shareholders, which amounts to maximization of

$$
\sum_{s \in S} \pi_{s} v^{\prime}\left(D^{\prime}(s) ; s\right)\left[B^{k}(s)-\rho(s) M^{k}(s)+\left(\rho(s)-r^{d}\right) D^{k}\right] .
$$

Here $M^{k}(s)$ and $B^{k}(s)$ denote the total amount of money borrowed from bank $k$ and the total amount that households must repay at the end of the period as a result; each of these depends upon the loan commitments entered into by the bank at the negotiation stage, and upon the state-dependent behavior of household members during the execution phase. The bank also chooses the quantity of deposits $D^{k}$ to bid for at the beginning of the period so as to maximize (1.12), given the market interest rate $r^{d}$ and its expectations regarding the state-dependent interbank rate $\{\rho(s)\}$.

It then follows that, given initial household wealth $D$, a state-dependent value function $\{v(\cdot ; s)\}$ and expected state-contingent government transfers $\{T(s)\}$, a temporary equilibrium consists of an interest rate $r^{d}$ for deposits, a specification of goods and loan supply commitments $\left(\bar{c}_{i}, p_{i}(\cdot) ; \bar{M}_{i}, r_{i}(\cdot)\right)$ for each type $i$, state-contingent consumption and borrowing plans $\left\{c_{i}(s), M_{i}(s)\right\}$ for each type, a state-contingent interbank funds rate $\{\rho(s)\}$, state-contingent profit distributions $\{\Pi(s)\}$, and statecontingent end-of-period household wealth $\left\{D^{\prime}(s)\right\}$, such that

(i) given $r^{d},\{\rho(s)\}$, and $\left\{D^{\prime}(s)\right\}$, the total demand for deposits on the part of banks equals the supply of deposits $D$;

(ii) goods supply commitments maximize (1.11) for each firm subject to its capacity constraint, given $\left\{D^{\prime}(s)\right\}$ and the state-contingent spending behavior of household members;

(iii) loan commitments maximize (1.12) for each bank, given $\left\{D^{\prime}(s), \rho(s)\right\}$ and the state-contingent borrowing behavior of household members;

(iv) for each type $i$ and each state $s,\left(c_{i}(s), M_{i}(s)\right)$ maximize (1.9) subject to (1.5) and (1.8), given $r^{d}, \Pi(s), T(s)$, and the spending and borrowing decisions of the other types;

(v) in each state $s, \rho(s)$ and the $\left\{M_{i}(s)\right\}$ satisfy (1.6); and

(vi) in each state $s, \Pi(s)$ is given by (1.7) and $D^{\prime}(s)$ by (1.8).

Such an ensemble describes equilibrium within a given period, taking as given the predetermined state variable $D$ through which past events affect current conditions, and taking as given the expectations about future conditions that are relevant for current decision-making (summarized by the value function $v(\cdot ; s)$ ).

A full intertemporal equilibrium is a sequence of specifications of $D,\{v(\cdot ; s)\}$, and an associated temporary equilibrium for each period, that in addition are such that 
(a) in each period, the initial wealth $D$ is the value that results from (1.8) in the temporary equilbrium of the previous period; and

(b) in each period, and for each state $s$, the value function $v(\cdot ; s)$ represents the maximum value of (1.9) that a household would be able to obtain in the temporary equilibrium of the following period, for any level of wealth that it may carry into that period.

Here we shall restrict our attention to the special case of a stationary equilibrium, in which $D,\{v(\cdot ; s)\}$ are the same each period, and similarly all other aspects of the temporary equilibrium each period. Such an equilibrium is possible in the case of a monetary policy rule (described by the funds supply correspondence $\Gamma$ ) that is the same each period, and a fiscal policy rule such that

$$
T(s)=(\rho(s)-1)(M(s)-D)
$$

at all times, i.e., one in which the government rebates to households the interest earned on its lending to the banks in the interbank funds market. Substitution of this into (1.8), using (1.7), implies that $D^{\prime}(s)=D$ regardless of the state $s$ that is realized. In this case, the nominal value of deposits held by each household in equilibrium never changes over time. It is then natural to consider the possibility of an equilibrium in which prices and interest rates are similarly unchanged over time. From here on, we consider only equilibria of this kind, and furthermore assume that the constant level of deposits $D$ is positive, so that the lower bound on end-of-period wealth never binds in equilibrium.

Stationarity has an important consequence, apart from the fact that each of equations (1.2) - (1.13) applies equally to every period. This is that the shadow value to households of additional end-of-period wealth, $v^{\prime}\left(D^{\prime} ; s\right)$, is the same in all states $s$. Let us write $\nu>0$ for this common value. This allows simplification of expressions (1.11) and (1.12); the objective of both firms and banks turns out to be simply the maximization of expected profits.

\section{Characterization of Stationary Equilibrium}

We now turn to a more detailed characterization of stationary equilibrium in the model of the previous section. We shall proceed in stages, describing first the equilibrium supply behavior of firms without reference to the specific character of the stochastic variations in demand that occur, and only subsequently considering the consequences of the kind of taste shocks assumed in (1.1).

\subsection{Equilibrium Supply Commitments with Uncertain De- mand}

Competitive equilibrium in the market for supply contracts at the negotiation stage results in the existence of a single quantity limit $\bar{c}_{i}$ and a single equilibrium supply 
function $p_{i}(\cdot)$ for each type $i$. We assume that there is competition between firms to supply the next increment of the good purchased by any buyer of type $i$ who has already purchased quantity $c$ (for any $0 \leq c<\bar{c}_{i}$ ); then $p_{i}(c)$ is the market-clearing price for such commitments. The analysis is simplified if we assume that a firm is unable to distinguish whether the buyer obtaining an incremental commitment has obtained his prior supply commitment from the same seller or from someone else, and is similarly unable to observe the terms of the buyer's prior supply commitments; but it is assumed that a seller can verify the total quantity already purchased at the time that the buyer places an order under the commitment. Then there is clearly a single market-clearing price depending only upon the type $i$ and the previously purchased quantity $c$. The equilibrium quantity limit $\bar{c}_{i}$ represents the lowest quantity such that no seller is willing to offer further commitments to buyers of type $i$ who have already purchased that amount of the good.

In the negotiation stage, buyers of type $i$ voluntarily accept price commitments up to the quantity limit $\bar{c}_{i}$, of the form indicated by the equilibrium supply function $p_{i}(c)$. (Since buyers are not obligated to make any purchases, there is no reason not to keep accepting incremental commitments, at the lowest prices at which they are available.) Firms choose the quantity of commitments that they wish to make to buyers of each type, at the competitive prices for each possible type of incremental commitment. Equilibrium requires that firms choose to supply exactly the quantity of commitments that buyers demand, which is to say exactly one full commitment (allowing purchases up to $\bar{c}_{i}$ ) per buyer of type $i$. In addition, equilibrium requires that no firm be willing to offer incremental commitments at prices lower than the equilibrium prices, or be willing to offer incremental commitments beyond the equilibrium quantity limit $\bar{c}_{i}$ at any finite price.

In the execution stage, each buyer of type $i$ decides what quantity $0 \leq c_{i} \leq \bar{c}_{i}$ to purchase, given the state $s$ that is realized. The purchasing decision $c_{i}(s)$ depends upon the commitment $\left(\bar{c}_{i}, p_{i}(\cdot)\right)$ obtained during the negotiation stage. Rational anticipation of this decision, in turn, determines the willingness of firms to extend such commitments during the negotiation stage. Individual firms take as given the equilibrium values $\left\{c_{i}(s)\right\}$, just as they do the equilibrium supply terms $\left\{\bar{c}_{i}, p_{i}(\cdot)\right\}$, in deciding which supply commitments to offer. Expected revenues per unit of capacity committed, in the case of incremental supply commitments to buyers of type $i$ who have already purchased quantity $c$, are equal to

$$
p_{i}(c) \sum_{s} \pi_{s} I\left(c_{i}(s)>c\right),
$$

where $I(x)$ is the function whose value is 1 if statement $x$ is true, and 0 otherwise.

A supply commitment to a given buyer can be made only if it is feasible for the firm to honor the commitment with certainty. It follows that optimization by a firm requires that each unit of capacity be committed in the way that yields the highest expected revenues. As in equilibrium it is necessary that supply commitments be 
made to each type of buyer, up to the quantity limit $\bar{c}_{i}$, it follows that one must have

$$
p_{i}(c) \sum_{s} \pi_{s} I\left(c_{i}(s)>c\right)=\lambda
$$

for each $i$ and each $0 \leq c<\bar{c}_{i}$. Here $\lambda$ indicates the maximum available expected revenues per unit of capacity. Furthermore, if $\lambda>0$, optimization by a firm requires that all capacity be committed. (We assume that the same communication barriers during the execution stage that prevent organization of a centralized market also preclude purchases from being made other than under previously negotiated commitments.) Thus equilibrium requires that if $\lambda>0,(1.3)$ holds with equality.

But equilibrium in the negotiation stage requires more than mere indifference on the part of firms between the various types of supply commitments that are actually offered in equilibrium; firms must also be content not to offer any of those that are not offered in equilibrium. There is plainly no point in a firm's offering an incremental supply commitment to buyers of type $i$ after a quantity $c$ has been purchased at a price $p>p_{i}(c)$, since no buyer will accept such a commitment, given the availability of supply commitments at a lower price. In the case of a quantity $c$ such that in every state, either $c_{i}(s)<c$ or $c_{i}(s)>c$, there is equally plainly no point in offering an incremental supply commitment at a price $p<p_{i}(c)$. For in states $s$ in which $c_{i}(s)<c$ without the price reduction, the incremental commitment will not be drawn upon despite the lower price, while in states $s$ in which $c_{i}(s)>c$ without the price reduction, it would be drawn upon even if the price were $p_{i}(c)$. Hence such a price reduction can only reduce expected revenues per unit of capacity so committed.

A more complex case is that of a quantity $c$ such that $c_{i}(s)=c$ for some state $s$. This means that at the equilibrium incremental supply price $p_{i}(c)$, buyers choose not to draw upon the commitment in state $s$. However, it may be that they would purchase more in state $s$ in the case of an incremental supply commitment at some lower price, and so we must consider whether a firm could increase expected revenues by offering such a commitment. Consideration of this requires that we specify what firms expect about whether additional commitments, not offered in equilibrium, would be drawn upon in various states. Given the equilibrium commitment $\left(\bar{c}_{i}, p_{i}(\cdot)\right)$, the determinants of type $i$ demand (further specified in the next section) determine not only the quantity $c_{i}(s)$ that is purchased in state $s$ under that commitment, but also the lowest price $\hat{p}_{i}(s)$ at which type $i$ would be willing to buy an additional positive quantity, after having purchased $c_{i}(s)$ under the equilibrium commitment. (Technically, we shall use $\hat{p}_{i}(s)$ to denote the greatest lower bound of the set of such prices.) An incremental commitment to buyers of type $i$ after purchases of a quantity $c$ at a price $p \leq p_{i}(c)$ will thus be accepted by such buyers in the negotiation stage, and drawn upon in the execution stage with probability

$$
\sum_{s} \pi_{s}\left[I\left(c_{i}(s)>c\right)+I\left(c_{i}(s)=c\right) I\left(\hat{p}_{i}(s)>p\right)\right] .
$$

(Note that this reduces to $\sum_{g} \pi_{s} I\left(c_{i}(s)>c\right)$, as assumed in $(2.1)$, in the case that $p=p_{i}(c)$, for one must have $\hat{p}_{i}(s) \leq p_{i}\left(c_{i}(s)\right)$ in every state.) 
Expected revenues per unit of capacity committed under incremental commitments of this kind are just $p$ times this probability. It follows that a further requirement for equilibrium is that

$$
p \sum_{s} \pi_{s}\left[I\left(c_{i}(s)>c\right)+I\left(c_{i}(s)=c\right) I\left(\hat{p}_{i}(s)>p\right)\right] \leq \lambda
$$

for all types $i$ and all prices $p \leq p_{i}(c)$, in the case of any quantity $0 \leq c<\bar{c}_{i}$. Furthermore, condition (2.2) must hold for all types $i$ and all prices $p$, in the case that $c=\bar{c}_{i}$; for only if this is so will firms not wish to increase the quantity limit $\bar{c}_{i}$.

Conditions $(2.1)-(2.2)$, together with the requirement that (1.3) hold with equality, determine the equilibrium supply commitments $\left\{\bar{c}_{i}, p_{i}(\cdot)\right\}$, given a specification of the determinants of buyer demand in each state $s$. Detailed characterization of such an equilibrium is not possible without further analysis of buyer behavior. Still, several observations are already possible as to the nature of aggregate supply.

It is shown below that for each buyer type $i$, if $s^{\prime} \geq s$, then $c_{i}\left(s^{\prime}\right) \geq c_{i}(s)$; and if $c_{i}\left(s^{\prime}\right)=c_{i}(s)$, then $\hat{p}_{i}\left(s^{\prime}\right) \geq \hat{p}_{i}(s)$. Thus higher $s$ corresponds to a state of uniformly higher demand. Then it follows from $(2.1)$ that each equilibrium supply schedule $p_{i}(\cdot)$ is a non-decreasing, piecewise constant function, of the form

$$
p_{i}(c)=p_{s} \quad \text { for all } \quad c_{i}(s-1) \leq c<c_{i}(s)
$$

for each $s$ such that $c_{i}(s)>c_{i}(s-1)$, where $c_{i}(0) \equiv 0$. The sequence of prices $\left\{p_{s}\right\}$ is furthermore given by

$$
p_{s}=\lambda\left[\sum_{s^{\prime} \geq \mathbf{s}} \pi_{s^{\prime}}\right]^{-1}
$$

for each state $s^{\prime}$. In the case that $\lambda>0$, this is an increasing sequence of positive prices. (It is shown below that this is the only possible type of equilibrium.) Note that these prices are the same for all types $i$. Condition (2.1) also implies that for any $c<\bar{c}_{i}$, there exists a state in which $c_{i}(s)>c$, so that $\bar{c}_{i}=c_{i}(\bar{s})$. Thus (2.3) specifies $p_{i}(\cdot)$ over its entire domain $\left[0, \bar{c}_{i}\right)$.

Condition (2.3) implies that every order that is placed if and only if a state $s^{\prime} \geq s$ occurs is made at the same price $p_{s}$, regardless of the buyer's type. If we rank orders so that orders that are placed in a larger number of states have an earlier rank, then the price associated with each order is a function solely of its rank (independent of the type of buyer). This price is given by an aggregate supply schedule $p(\cdot)$, a function defined on $[0, y)$, such that $p(c)$ is the next price at which orders are placed when aggregate purchases in excess of $c$ are made. Conditions (2.3)-(2.4) imply that $p(\cdot)$ is a non-decreasing, piecewise constant function, of the form (2.3), but with thresholds defined by the successive quantities $\{c(s)\}$.

It is now apparent that unexpected variations in the nominal value of aggregate spending - unexpected, that is, relative to information available during the negotiation stage - must be associated with variations in capacity utilization. For aggregate spending is given by $Y(s)=R(c(s))$, where $R(\cdot)$ is the integral of $p(\cdot)$ as in (1.2). 
This implies that if $Y\left(s^{\prime}\right)>Y(s)$, one must have $c\left(s^{\prime}\right)>c(s)$ as well, so that the fraction of total capacity $y$ that is unused must be lower in state $s^{\prime}$.

The way in which unexpected variations in aggregate spending result in variations in capacity utilization here is essentially the same as in the superficially dissimilar models of Lucas and Woodford (1994) and Eden (1994), even though those models assume a different ultimate source for the variations in aggregate spending (i.e., stochastic monetary policy). In the model of Lucas and Woodford, a sequential service constraint similar to that imposed here is assumed, though there are no supply commitments made in advance to particular buyers, and buyers simply place orders with sellers when they find one willing to supply them at a low enough price. The equilibrium relations linking the state of demand, transactions prices, and quantities purchased are the same as those derived here; the model of aggregate supply set out in this section is essentially equivalent to theirs in the case that all buyers are of a single type.

In Eden's model, there is a sequence of competitive spot markets, one before anything is known about the state of demand, another after it is revealed that the lowest-demand state has not occurred (if it has not), and so on. The number of markets that occur is greater the higher the state of demand. The sequence of prices $\left\{p_{s}\right\}$ derived above corresponds, in Eden's model, to the market-clearing prices in this succession of spot markets, when they occur. Again, the equilibrium relations linking the state of demand, transactions prices, and quantities purchased are the same as are derived here.

An advantage of the formalism introduced here, relative to either of the variants just discussed, is that the distinct transactions prices $\left\{p_{s}\right\}$ are not represented as relating to purchases that occur in any particular temporal order. Thus the present model predicts that one should in general observe a non-degenerate distribution of prices at which similar goods are simultaneously offered for sale, as one does. But it does not predict that, say, all similar goods sold on Monday at 10 a.m. should sell for the same price, but that this price should be lower than the price for which goods of this type are sold on Monday at 2 p.m.- a prediction of the earlier models, if taken literally, that is certainly not verified in reality. The present formalism is also convenient, for present purposes, in that it provides a clear reason for buyers whose demands are cyclical to varying degrees to face different supply prices; this effect (for which there is empirical support) turns out to be important for the welfare analysis of alternative monetary policies.

\subsection{Monetary Policy and Equilibrium Loan Commitments}

The form of equilibrium loan commitments can be characterized along lines similar to those of the previous subsection, again deferring a complete analysis of the extent to which such commitments will be exercised in different aggregate states. The main difference in the analysis in the case of the consumer credit market is that there is no analog here of firms' capacity constraint; instead, a bank that extends an additional 
commitment simply understands that it must borrow funds in the interbank market, in those states in which the commitment is actually exercised. Monetary policy, by determining the state-dependent interest rate at which such funds will be available, is thus a crucial determinant of the form of equilibrium loan commitments.

As explained in section 1, monetary policy is described by a funds supply correspondence $\Gamma$, indicating the pairs of interest rates $\rho$ and net supplies of funds $F$ that are consistent with the central bank's supply rule. (Because of (1.6), this is equivalent to a rule that determines the money supply as a function of the interest rate in the interbank market.) This correspondence is a non-empty subset of the Euclidean plane, assumed to satisfy the following properties:

(i) if $(\rho, F),\left(\rho^{\prime}, F^{\prime}\right) \in \Gamma$, and $\rho^{\prime}>\rho$, then $F^{\prime} \geq F$; similarly, if $F^{\prime}>F$, then $\rho^{\prime} \geq \rho$; and

(ii) for any $(\rho, F) \in \Gamma$, there exists another point $\left(\rho^{\prime}, F^{\prime}\right) \in \Gamma$, with $\rho^{\prime} \geq \rho, F^{\prime} \geq F$, and at least one inequality strict; similarly, there exists another point $\left(\rho^{\prime}, F^{\prime}\right) \in$ $\Gamma$, with $\rho^{\prime} \leq \rho, F^{\prime} \leq F$, and at least one inequality strict.

Condition (i) is a weak monotonicity requirement; alternative monetary policies thus amount to different decisions as to how rapidly or slowly interest rates will be allowed to rise in the interbank market in response to an increase in the net demand for funds. Condition (ii) implies that the correspondence gives a complete description of the central bank's stance in the face of an arbitrarily high or low net demand for funds.

It is useful to distinguish between two possible classes of policies, that I shall call direct and indirect monetary policies. Under a direct policy, the central bank directly controls the volume of credit extended to households by banks, and hence the money supply, whereas under an indirect policy the central bank restricts itself to control simply of the supply of funds to banks in the interbank market. In terms of the formalism just introduced, a direct policy corresponds to the choice of a correspondence with properties (i) - (ii), whereas in the case of an indirect policy the funds supply correspondence must satisfy an additional property:

(iii) if $(\rho, F) \in \Gamma, \rho \geq 1$.

Condition (iii) must be satisfied in the case of an indirect policy, because if the central bank does not monitor the lending of the banks, then it cannot prevent them, in the case of a negative interest rate in the interbank market $(\rho<1)$, from borrowing an arbitrarily large quantity of funds and simply holding them rather than lending them out. Hence equilibrium in the interbank market cannot involve an interest rate less than $\rho=1$, and we can represent this as a constraint on the possible supply correspondences of the central bank (in which case we need not introduce notation for a distinction between the quantity that banks loan and the quantity that they borrow in the interbank market). In the case of a direct policy, by contrast, the central bank can provide incentives for banks to actually lend, and not simply to 
borrow from the central bank, and so equilibria are possible with negative interest rates in the interbank market. Thus the class of possible indirect policies is a proper subset of the class of possible direct policies.

We turn now to the characterization of equilibrium interest rates and the equilibrium supply of loan commitments, given such a policy. Maximization of expected profits by banks in their bidding for deposits at the beginning of the period, together with households' supply of deposits in the quantity $D>0$, implies that this market clears if and only if

$$
r^{d}=\sum_{s} \pi_{s} \rho(s) .
$$

Similarly, maximization of expected profits implies that in the negotiation stage, any bank will be willing to supply incremental loan commitments at an interest rate equal to the expected value of $\rho(s)$ in the interbank market, conditional upon the loan commitment's being drawn upon. Thus each loan supply schedule $r_{i}(\cdot)$ must satisfy

$$
r_{i}(M)=\frac{\sum_{s} \pi_{s} \rho(s) I\left(M_{i}(s)>M\right)}{\sum_{g} \pi_{s} I\left(M_{i}(s)>M\right)}
$$

for all $0 \leq M<M_{i}(\bar{s})$. We may without loss of generality assume that banks do not bother to offer commitments that they know will never be drawn upon, so that $\bar{M}_{i}=M_{i}(\bar{s})$ for each $i$. Then (2.6) defines $r_{i}(\cdot)$ over its entire domain.

Another necessary condition for equilibrium in the credit market during the negotiation stage is that $r_{i}(M) \geq 1$ over the entire domain of the function. In the case of an indirect monetary policy, this follows from (2.6). However, it is necessary for equilibrium even if negative interest rates are possible in the interbank market. This is because no bank could expect to gain by offering an incremental loan commitment at an interest rate $r<1$, rather than some other rate $r^{\prime}$ with $r<r^{\prime}<1$. For a buyer with either commitment will draw upon it with certainty, in any state in which he borrows quantity $M$ and thus becomes eligible to do so. (The money thus borrowed need not be spent; part could simply be held in order to repay the loan at the end of the period.) Furthermore, there is no possibility that competition between banks could force them to offer commitments at the rate $r$. For if other banks offer incremental commitments at that rate, a bank can offer its own commitment at the rate $r^{\prime}$, to apply after the borrower has already borrowed $M^{\prime}$, where $M^{\prime}-M$ is the quantity of commitments obtained at the lower interest rate. Such an incremental commitment will still be accepted (as it does not preclude acceptance of the lower-rate loan commitments first), and it is exercised in the same states as the other ones (since whenever the buyer borrows $M$, he will borrow $M^{\prime}$, given the negative cost of the additional borrowing); therefore it results in higher expected revenues. This conclusion does not contradict the necessity of (2.6); it simply means that the equilibrium interest rates in the interbank market must be such that the right hand side of (2.6) is never lower than 1, lest an arbitrage opportunity be created for banks.

It is shown in the next subsection that $\left\{M_{i}(s)\right\}$ is a non-decreasing series. It then follows from (2.6) that each equilibrium loan supply schedule is a piecewise constant 
function, of the form

$$
r_{i}(M)=r_{s} \quad \text { for all } \quad M_{i}(s-1) \leq M<M_{i}(s)
$$

for each state $s$ such that $M_{i}(s)>M_{i}(s-1)$, where $M_{i}(0) \equiv 0$. The sequence of interest rates $\left\{r_{s}\right\}$ referred to in (2.7) is given by

$$
r_{s}=\frac{\sum_{s^{\prime} \geq s} \pi_{s^{\prime}} \rho\left(s^{\prime}\right)}{\sum_{s^{\prime} \geq s} \pi_{s^{\prime}}} .
$$

Furthermore, aggregate borrowing $\{M(s)\}$ is also a non-decreasing series. Given the monotonicity assumption on $\Gamma$ (condition (i) above), this implies that the series $\{\rho(s)\}$ must be non-decreasing, except possibly in the case of successive states over which $M(s)$ remains constant, at a value corresponding to a vertical segment of the correspondence $\Gamma$. We shall impose as a further regularity condition on equilibria that $\{\rho(s)\}$ be a non-decreasing series in such a case as well. (This amounts to consideration only of equilibria that can be approximated arbitrarily closely by equilibria associated with monetary policies which make the money supply a well-defined, increasing function of $\rho$.) Then (2.8) implies that the series $\left\{r_{s}\right\}$ is non-decreasing as well. Finally, comparison of (2.8) with (2.5) indicates that $r_{1}=r^{d}$, so that $r_{i}(M) \geq r^{d}$ for all $i$ and all $M \geq 0$.

As in the analysis above of goods supply commitments, optimization again requires also that expected profits be non-positive in the case of all loan commitments that are not offered in equilibrium. We can strengthen the requirements for equilibrium, by demanding not merely that no firm wish to offer any other supply commitments given the equilibrium loan commitments, and that no bank wish to offer any other loan commitments given the equilibrium supply commitments of sellers, but furthermore that there be no joint deviation by a firm and a bank that would be jointly profitable. 16 Note that it suffices to consider the condition under which the combination of an incremental goods supply commitment and an incremental loan commitment would induce an increase in the goods purchased in some state, and a corresponding increase in the money borrowed to pay for those additional purchases. For the only case in which a borrower could be induced to borrow additional funds in some state and not use them for increased purchases is if the interest rate for the incremental borrowing is zero $(r=1)$. Such an incremental loan would only create positive expected profits for the lender if at the level of borrowing $M$ at which the incremental loan is offered,

$$
\sum_{s} \pi_{s} \rho(s) I\left(M_{i}(s)>M\right)<\sum_{s} \pi_{s} I\left(M_{i}(s)>M\right) .
$$

But this would violate the necessary condition for equilibrium already stated above, that the right hand side of (2.6) be no less than 1 for any $M$.

\footnotetext{
${ }^{16}$ This amounts to a refinement of our equilibrium concept, that allows for mutually beneficial coordination of the supply behavior of more than one entity, as long as such coalitions never involve a non-negligible fraction of the suppliers in any market.
} 
It has been shown in the next subsection that a household member of type $i$ would make use of an incremental supply commitment beyond the point $c=c_{i}(s)$ and an incremental loan commitment beyond the point $M=R_{i}\left(c_{i}(s)\right)$, in state $s$, if and only if the incremental supply price $p$ and the incremental interest rate $r$ are such that $p \leq p_{i}(c), r \leq r_{i}(M)$, and $p r<\hat{e}_{i}(s)$, for a certain threshold $\hat{e}_{i}(s)$ that is there characterized. For present purposes, it suffices to note that

$$
\hat{e}_{i}(s) \leq p_{i}\left(c_{i}(s)\right) r_{i}\left(R_{i}\left(c_{i}(s)\right)\right) .
$$

In fact, the threshold price $\hat{p}_{i}(s)$ referred to in (2.2) is derivable from this threshold, through the relation

$$
\hat{p}_{i}(s)=\hat{e}_{i}(s) / r_{i}\left(R_{i}\left(c_{i}(s)\right)\right) .
$$

It is then a requirement for equilibrium that for each type $i$, and for any quantity $0 \leq c<\bar{c}_{i}$, there exists no price $p \leq p_{i}(c)$ and interest rate $r \leq r_{i}\left(R_{i}(c)\right)$ such that

$$
p \sum_{s} \pi_{s}\left[I\left(c_{i}(s)>c\right)+I\left(c_{i}(s)=c\right) I\left(\hat{e}_{i}(s)>p r\right)\right] \geq \lambda
$$

and

$$
\sum_{s} \pi_{s}(r-\rho(s))\left[I\left(c_{i}(s)>c\right)+I\left(c_{i}(s)=c\right) I\left(\hat{e}_{i}(s)>p r\right)\right] \geq 0,
$$

unless both (2.11) - (2.12) hold with equality. For if such a pair $(p, r)$ were to exist, it would represent a joint incremental commitment that would increase the expected profits of at least one party (the firm or the bank), without reducing the expected profits of the other. Similarly, in the case that $c=\bar{c}_{i}$, there must exist no pair $(p, r)$ that satisfy (2.11) $-(2.12)$, unless both hold with equality.

Note that in the case that $c=c_{i}(s)$ and $r=r_{i}\left(R_{i}(c)\right)$, the left hand side of $(2.12)$ is equal to zero when $p=p_{i}(c)$, using (2.6) and (2.9). It then follows that (2.12) holds for all $p \leq p_{i}(c)$. Hence for this choice of $r$, there must exist no $p \leq p_{i}(c)$ for which (2.11) holds, unless it holds with equality. But, using (2.10), this requirement is seen to be equivalent to (2.2). Thus requirements (2.11) - (2.12) imply (2.2), and can be regarded as an extension of the previous requirement.

Now in the case that $c$ does not equal $c_{i}(s)$ for any state $s$, requirements (2.11) (2.12) are implied by (2.3) - (2.4) and (2.7) - (2.8). If $c=c_{i}(s)$ for some state $s$, one can show that the requirements are satisfied if and only if

$$
\hat{e}_{i}(s) \leq p_{s} r_{s}
$$

for each state $s$ such that $s=1$, or that $c_{i}(s)>c_{i}(s-1)$, or that $c_{i}(s)=c_{i}(s-1)$ but $\left.\hat{e}_{i}(s)>\hat{e}^{i}(s-1)\right)$.

Furthermore, the fact that (2.7) holds for all states in the classes just listed implies that it must hold for all states. For in the case of any sequence of states $\left(s^{\prime}, \ldots, s^{\prime}+j\right)$ such that $c_{i}\left(s^{\prime}+k\right)=c_{i}\left(s^{\prime}\right)$ and $\hat{e}_{i}\left(s^{\prime}+k\right)=\hat{e}_{i}\left(s^{\prime}\right)$ for all $0 \leq k \leq j,(2.7)$ must hold for state $s^{\prime}$ as long as $s^{\prime}-1$ does not also have the same property. But then the fact that series $\left\{p_{s}\right\}$ and $\left\{r_{s}\right\}$ are both non-decreasing implies that (2.7) holds as 
well for each of the states $\left(s^{\prime}, \ldots, s^{\prime}+j\right)$. Thus (2.7) must hold for all states. This provides a complete characterization of equilibrium loan supply commitments (once the quantities $\left\{M_{i}(s)\right\}$ are determined), analogous to that provided by (2.4) in the case of goods supply commitments.

\subsection{Preference Shocks, Spending and Borrowing}

Household spending and borrowing decisions in the execution phase remain to be characterized. These depend upon the state $s$ because such states differ with respect to the population distribution of preferences for current consumption; this dependence is the source of the stochastic variations in aggregate demand to which monetary policy may be more or less accommodative.

As explained in section 1, the household's problem is to maximize (1.9) subject to (1.5) and (1.8), given the value function $v(\cdot ; s)$ and the value of $r^{d} D+\Pi(s)+T(s)$. Note that for any household member of type $i$, consumption purchases $c$ are feasible if and only if $0 \leq c \leq \bar{c}_{i}, 0 \leq R_{i}(c) \leq \bar{M}_{i}$. The feasible range is thus $\left[0, c_{i} *\right]$, where $c_{i} *=\bar{c}_{i}$ if $\bar{M}_{i} \geq R_{i}\left(\bar{c}_{i}\right)$, and $c_{i} *=R_{i}^{-1}\left(\bar{M}_{i}\right)$ otherwise. Now let $E_{i}(c)$ denote the total cost for type $i$ of purchasing a quantity $c$, counting both the direct cost of the purchases and the interest paid for the cash borrowed to make the purchases, given the supply commitments obtained during the negotiation stage, assuming that the quantity of cash borrowed is chosen so as to minimize this cost, consistent with satisfaction of the cash-in-advance constraint. Then the household's problem reduces to the choice of $\left\{c_{i}(s)\right\}$ so as to maximize (1.9) subject to the budget constraint

$$
D^{\prime}(s)=r^{d} D+\Pi(s)+T(s)-\sum_{i} n_{i} E_{i}\left(c_{i}(s)\right) .
$$

We have shown in the previous subsections that $\left(p_{i}(\cdot), r_{i}(\cdot)\right)$ are both non-decreasing functions over their respective domains, with $p_{i}(c)>0$ for all $c$ and $r_{i}(M) \geq 1$ for all $M$. It follows that $E_{i}(c)=B_{i}\left(R_{i}(c)\right)$, and that this is an increasing, convex function on the domain $\left[0, c_{i} *\right.$, with $E_{i}(0)=0$. Maximization of (1.9) subject to (2.14) then requires that $c_{i}(s)$ be chosen so that

$$
\frac{\delta_{i}(s) u^{\prime}\left(c_{i}(s)\right)}{\beta v^{\prime}\left(D^{\prime}(s) ; s\right)} \in \partial E_{i}\left(c_{i}(s)\right),
$$

for each $i$, where $\partial E_{i}$ denotes the subdifferential of $E_{i}(\cdot)$ (Rockafellar (1970)). That is, for any $0 \leq \tilde{c} \leq c_{i} *$,

$$
\partial E_{i}(\tilde{c}) \equiv\left\{\lambda \geq 0 \mid E_{i}(c) \geq E_{i}(\tilde{c})+\lambda(c-\tilde{c}) \text { for all } 0 \leq c \leq c_{i} *\right\}
$$

It is evident that $\partial E_{i}$ is a non-decreasing, closed and convex-valued, upper-hemicontinuous correspondence, such that $0 \in \partial E_{i}(0)$, that $0 \notin \partial E_{i}(c)$ for any $c>0$, and that $\sup \partial E_{i}\left(c_{i} *\right)=\infty$. It then follows (given the monotonicity and concavity of $u(\cdot)$ and $v(\cdot ; s)$, and strict concavity of $u(\cdot))$ that $(2.15)$ is satisfied by exactly one set of consumption plans $\left\{c_{i}(s)\right\}$. 
In the case of a stationary equilibrium, we furthermore must have the same value $v^{\prime}\left(D^{\prime}(s) ; s\right)=\nu>0$ in each state $s$, as explained at the end of section 1. Then (2.15) reduces to

$$
(\beta \nu)^{-1} \delta_{i}(s) u^{\prime}\left(c_{i}(s)\right) \in \partial E_{i}\left(c_{i}(s)\right),
$$

for each $i$. This relation plainly suffices to uniquely determine $c_{i}(s)$, given $\nu$ (that remains to be determined) and the goods and loan supply commitments for type $i$ (the determination of which were treated in the previous two subsections). Condition (2.16) indicates how each household's demand depends upon its type and the state $s$ that is realized. It follows from this (and the monotonicity of $u^{\prime}$ and $\partial E_{i}$ ) that a state with a higher value of $\delta_{i}(s)$ must result in a higher value of $c_{i}(s)$. Hence the weak monotonicity of $\delta_{i}(s)$ in $s$ implies that $c_{\boldsymbol{i}}(s)$ is also non-decreasing in $s$, as asserted earlier.

Optimal borrowing then must satisfy the cash-in-advance constraint (1.5), together with the complementary slackness condition

$$
\left[r_{i}\left(R_{i}\left(c_{i}(s)\right)\right)-1\right]\left[M_{i}(s)-R_{i}\left(c_{i}(s)\right)\right]=0 .
$$

In the event that $r_{i}(M)>1$ for all $M$ (as we shall show is always true in a stationary equilibrium), this implies that

$$
M_{i}(s)=R_{i}\left(c_{i}(s)\right),
$$

so that $M_{i}(s)$ is uniquely determined as well. Because $c_{i}(s)$ is non-decreasing in $s$, (2.17) implies that $M_{i}(s)$ is also non-decreasing in $s$, as asserted earlier.

These relations determine households, state-contingent spending and borrowing, given the supply commitments offered by firms and banks. However, as noted earlier, equilibrium supply behavior depends upon suppliers' understanding of the conditions under which household members would make use of additional supply commitments (not actually offered them in equilibrium). It remains to specify this aspect of household behavior.

Consider a household member of type $i$ in the case of state $s$. Given the equilibrium supply commitments, the buyer chooses to purchase $c_{i}(s)$. It is evident from (2.16), however, that the buyer would have made use of an incremental supply commitment beyond this point, had additional goods been available beyond the quantity $c_{i}(s)$ at a price $p$, and loans been available beyond the quantity $R_{i}\left(c_{i}(s)\right)$ at an interest rate $r$, such that $p r<\hat{e}_{i}(s)$, where

$$
\hat{e}_{i}(s)=(\beta \nu)^{-1} \delta(s ; i) u^{\prime}\left(c_{i}(s)\right) .
$$

Note that (2.16) implies that $\hat{e}_{i}(s) \in \partial E_{i}\left(c_{i}(s)\right)$, and hence that $\hat{e}_{i}(s)$ satisfies (2.9), as asserted earlier. If we take as given the loan commitments, and consider only incentives to deviate from the equilibrium supply commitments on the part of firms (as in the section 2.1), then an incremental supply commitment beyond the quantity $c_{i}(s)$ at a price $p$ would be made use of in state $s$ if and only if $p<\hat{p}_{i}(s)$, where $\hat{p}_{i}(s)$ is defined by $(2.10)$. Note that $(2.9)-(2.10)$ imply that $\hat{p}_{i}(s) \leq p_{i}(s)$, as asserted 
earlier. Furthermore, if $s^{\prime} \geq s$ and $c_{i}\left(s^{\prime}\right)=c_{i}(s)$, then given (2.10), (2.18) implies that $\hat{p}_{i}\left(s^{\prime}\right) \geq \hat{p}_{i}(s)$, as asserted earlier.

It is now also possible to dispose of the possibility of equilibrium in which (2.4) holds with $\lambda=0$. Let us assume that for each type $i$, there exists a state $s$ for which $\delta_{i}(s)>0$, and let $\underline{s}_{i}$ be the lowest such state. (There is no loss of generality in ignoring types that never need to consume.) The assumption of weak monotonicity of $\delta_{i}(s)$ in $s$ implies that $\delta_{i}(s)>0$ for all $s \geq \underline{s}_{i}$. Then (2.18) implies that $\hat{e}^{i}(s)>0$ for all $s \geq \underline{s}_{i}$. But if $\lambda=0$, (2.4) would imply that the right hand side of (2.13) equals zero for all $s$, so that (2.13) would be violated in the states just mentioned. Thus equilibrium necessarily involves $\lambda>0$, as asserted earlier.

Finally, the shadow value of end-of-period wealth, $\nu$, remains to be determined. Because the constraint $D^{\prime}(s) \geq 0$ does not bind in any state, the envelope theorem implies that 17

$$
v_{t}^{\prime}\left(D_{t+1}\right)=\beta E_{t}\left\{r_{t+1}^{d} v_{t+1}^{\prime}\left(D_{t+2}\left(s_{t+1}\right) ; s_{t+1}\right)\right\}
$$

at each date $t$. In a stationary equilibrium, (2.19) reduces to $r^{d}=\beta^{-1}$, which, because of (2.5), implies that

$$
\sum_{s} \pi_{s} \rho(s)=\beta^{-1}
$$

This condition turns out not to imply any direct restriction upon the stationary value of $\nu$. However, it does supply an additional condition that must be satisfied in a stationary equilibrium, and since the considerations taken up earlier already sufficed to determine the stationary values of all other quantities given the value of $\nu$, condition (2.20) then determines the equilibrium value of $\nu$.

\subsection{Stationary Equilibrium}

Let us now consider the equilibrium that results from joint satisfaction of the various conditions derived in the preceding subsections. Using the characterizations (2.3) (2.4) and (2.7) $-(2.8)$ of equilibrium supply commitments, (2.16) becomes

$$
p_{s-(s)} r_{s-(s)} \leq(\beta \nu)^{-1} \delta_{i}(s) u^{\prime}\left(c_{i}(s)\right) \leq p_{s^{+}(s)} r_{s+(s)},
$$

where for each state $s, s^{-}(s)$ denotes the lowest state $s^{\prime}$ for which $c_{i}\left(s^{\prime}\right)=c_{i}(s)$, and $s^{+}(s)$ denotes the immediate successor to the highest state $s^{\prime}$ with this property. (If there is no higher state for which the property does not hold, then the second inequality in (2.21) is vacuous. Also, the first inequality does not apply if $c_{i}(s)=0$.) Substitution of (2.18) into (2.13) and comparison with (2.21) shows that the upper bound in (2.21) can be tightened, to yield

$$
p_{s-(s)} r_{s-(s)} \leq(\beta \nu)^{-1} \delta_{i}(s) u^{\prime}\left(c_{i}(s)\right) \leq p_{s} r_{s}
$$

where the first inequality again must hold only if $c_{i}(s)>0$. (Note that $p_{s} r_{s}$ cannot exceed $p_{s^{+}(s)} r_{s+(s)}$, because of the monotonicity of the series $\left\{p_{s}\right\}$ and $\left\{r_{s}\right\}$.)

\footnotetext{
${ }^{17}$ In writing (2.19), we suppress the arguments indicating the possible dependence of the various quantities upon the history of aggregate demand states in periods $t$ and earlier.
} 
It follows from (2.21) (or equivalently, (2.22)) that in any state $s<\underline{s}_{i}$, so that $\delta_{i}(s)=0$, one must have $c_{i}(s)=0$. (Note that (2.4) and (2.8) imply that $p_{s} r_{s}>0$ in all states, given that $\lambda>0$.) It is also necessary that $c_{i}(s) \geq c_{i}(s-1)$ for all $s \geq \underline{s}_{i}$ (where in the case $s=1$, we again define $c_{i}(0) \equiv 0$ ). If $c_{i}(s)>c_{i}(s-1), s^{-}(s)=s$, and (2.22) implies that

$$
u^{\prime}\left(c_{i}(s)\right)=\beta \nu \delta_{i}(s)^{-1} p_{s} r_{s} .
$$

On the other hand, if the second inequality in (2.11) is strict, one must have $s>s^{-}(s)$, so that one must have $c_{i}(s)=c_{i}(s-1)$, and hence $u^{\prime}\left(c_{i}(s)\right)=u^{\prime}\left(c_{i}(s-1)\right)$. Thus for all $s \geq \underline{s}_{i}$,

$$
u^{\prime}\left(c_{i}(s)\right)=\min \left[u^{\prime}\left(c_{i}(s-1), \beta \nu \delta_{i}(s)^{-1} p_{s} r_{s}\right],\right.
$$

from which it follows that

$$
u^{\prime}\left(c_{i}(s)\right)=\min \left[u^{\prime}(0), \min _{\underline{s}_{i} \leq s^{\prime} \leq s}\left\{\beta \nu \delta_{i}\left(s^{\prime}\right)^{-1} p_{s^{\prime}} r_{s^{\prime}}\right\}\right] .
$$

Given sequences $\left\{p_{s}, r_{s}\right\}$ and a value $\nu>0,(2.23)$ uniquely determines the sequence $\left\{c_{i}(s)\right\}$.

We may now collect our results characterizing stationary equilibrium. A stationary equilibrium is a set of three non-decreasing price series $\left\{p_{s}, r_{s}, \rho(s)\right\}$, a pair of nondecreasing quantity series $\left\{c_{i}(s), M_{i}(s)\right\}$ for each type $i$, and quantities $\lambda, \nu>0$, such that

(i) given $\lambda>0$, the prices $\left\{p_{s}\right\}$ are given by (2.4);

(ii) given the interbank market rates $\{\rho(s)\}$, the credit market rates $\left\{r_{s}\right\}$ are given by $(2.8)$;

(iii) given the prices $\left\{p_{s}, r_{s}\right\}$ and $\nu>0$, the consumption plans $\left\{c_{i}(s)\right\}$ are given by (2.23), together with the requirement that $c_{i}(s)=0$ for all $s<\underline{s}_{i}$, and the borrowing plans $\left\{M_{i}(s)\right\}$ are given by $(2.17)$, where the function $R_{i}(\cdot)$ is defined by (1.2) and (2.3);

(iv) given the plans $\left\{c_{i}(s), M_{i}(s)\right\}$, the quantity limits $\left\{\bar{c}_{i}, \bar{M}_{i}\right\}$ are given by $c_{i}(\bar{s})$ and $M_{i}(\bar{s})$ respectively;

(v) the quantity limits $\left\{\bar{c}_{i}\right\}$ satisfy (1.3);

(vi) the interbank market rates $\{\rho(s)\}$ and the plans $\left\{M_{i}(s)\right\}$ are such that (1.6) is satisfied for each state $s$, where $M(s)=\sum_{i} M_{i}(s)$; and

(vii) the interbank market rates $\{\rho(s)\}$ satisfy $(2.20)$.

For arbitarily chosen values for $\lambda, \nu>0$ and an arbitary series $\rho=\{\rho(s)\}$, conditions (i) - (iv) indicate how one may compute unique equilibrium values for the aggregate supply commitment $\bar{c} \equiv \sum_{i} n_{i} \bar{c}_{i}$, the expected interbank interest rate 
$\bar{\rho} \equiv \sum_{s} \pi_{s} \rho(s)$, and aggregate borrowing $M(s)$ in each state. Then such values for $(\lambda, \nu, \rho)$ describe a stationary equilibrium if and only if

$$
\begin{gathered}
\bar{c}(\lambda, \nu, \rho)=y, \\
\bar{\rho}(\rho)=\beta^{-1},
\end{gathered}
$$

and

$$
(\rho(s), M(s ; \lambda, \nu, \rho)-D) \in \Gamma
$$

for each state $s$. The number of independent equilibrium conditions in (2.24) is equal to the number of endogenous variables $(\lambda, \nu, \rho)$. This does not in itself prove that equilibrium is either possible or uniquely determined in the case of any particular monetary policy $\Gamma$, but should suggest that the proposed definition of equilibrium satisfies at least minimal standards of coherence. Rather than pursue further questions of existence or uniqueness of stationary equilibrium for general policies, we turn instead to the question of the policies that support desirable equilibria.

\section{Optimal Monetary Policy: Two Polar Cases}

We now turn to the question of optimal monetary policy. An obvious welfare criterion in the present context is the ex ante expected utility of the representative household. In a stationary equilibrium of the kind described above, this is proportional to the quantity

$$
W=\sum_{i} \sum_{s} \pi_{s} n_{i} \delta_{i}(s) u\left(c_{i}(s)\right) .
$$

I thus wish to compare the level of $W$ obtained in the alternative stationary equilibria associated with alternative possible central bank supply correspondences $\Gamma$.

Two opposing considerations can each be brought clearly into focus if we consider two polar cases in which the optimal policy has a simple characterization. The first polar case is that in which

$$
\delta_{i}(s)=\eta_{i} \delta(s)
$$

for each type $i$ and state $s$, for $\left\{\eta_{i}\right\}$ a set of positive weights and $\{\delta(s)\}$ an increasing, positive series. In this case, different states $s$ involve no change in the relative intensities of different types' tastes for current consumption, only uniform variation in all types' intensity of desire. We may say in this case that the demand fluctuations are entirely on the intensive margin. An opposing case is that in which

$$
\delta_{i}(s)=I\left(s \geq \underline{s}_{i}\right),
$$

where again $\left\{\eta_{i}\right\}$ is a set of positive weights, and where now for each state $s$, there exists at least one type $i$ for which $\underline{s}_{i}=s$. In this contrasting extreme case, preferences are the same, for any given type, across all the states in which that type desires to consume at all; what varies across states is the number of types with any desire to 
consume. We may say in this case that the demand fluctuations are entirely on the extensive margin.

In characterizing optimal policy in these cases, it is useful to begin by considering what the optimal state-contingent allocation of resources is like, and then asking if any monetary policy is consistent with it. Clearly, any feasible allocation of resources must satisfy the constraint

$$
\sum_{i} n_{i} c_{i}(s) \leq y
$$

in each state $s$. Let us call the allocation $\left\{c_{i}(s)\right\}$ that maximizes (3.1) subject to (3.4) holding in all states the first-best allocation. This is equivalent to choosing the allocation in each state to maximize $\sum_{i} n_{i} \delta_{i}(s) u\left(c_{i}(s)\right)$ subject to (3.4) in that state. Ignoring the case of corner solutions, the solution is characterized by the first-order conditions

$$
\delta_{i}(s) u^{\prime}\left(c_{i}(s)\right)=\alpha(s)
$$

for all $i$, where $\alpha(s)>0$ is determined by the requirement that (3.4) hold with equality.

This allocation will, however, seldom be achievable through any monetary policy. This is because the sequential service constraint upon goods supply commitments implies that in any equilibrium, the allocation of resources must satisfy

$$
c_{i}(s) \geq c_{i}(s-1)
$$

for each type $i$ and each state $s>1$. It is not possible to arrange for a given type to not be allowed to consume as much in a high-demand state as he or she is able to in a low-demand state, even though maximization of average expected utility would require it. Let us call the allocation $\left\{c_{i}(s)\right\}$ that maximizes (3.1) subject to (3.4) for all states and (3.6) for each type and all states the second-best allocation. In the second-best allocation, for each type $i, c_{i}(s)=\bar{c}_{i}$ for all $s \geq \underline{s}_{i}$, while $c_{i}(s)=0$ for states $s<\underline{s}_{i}$, if any. ${ }^{18}$ The second-best quantity limits $\left\{\bar{c}_{i}\right\}$ are characterized (again ignoring corner solutions) by the first-order conditions

$$
u^{\prime}\left(\bar{c}_{i}\right)=\alpha\left[\sum_{s} \pi_{s} \delta_{i}(s)\right]^{-1}
$$

for each $i$, where $\alpha>0$ is determined by the requirement that (1.3) hold with equality. It will be observed that in the polar case defined by (3.2), the first-best and secondbest allocations coincide; but this is essentially the only case in which they do.

Let us now consider optimal policy in that polar case, the case of demand fluctuations on the intensive margin only. In this case, there exists a direct monetary policy that achieves the first-best allocation; this is plainly an optimal policy, among

\footnotetext{
${ }^{18} \mathrm{As}$ far as the constrained maximization is concerned, consumption in states $s<\underline{s}_{i}$ need not equal zero, though this is one solution. We define this as the second-best allocation in order to obtain a unique allocation, and because this is the only kind of solution to the constrained maximum problem that can correspond to an equilibrium.
} 
the class of direct policies. The policy that achieves it is a constant-money-supply policy, i.e., a correspondence $\Gamma$ of the form

$$
\Gamma=\left\{(\rho, F) \mid F=F^{*}\right\},
$$

for any $F *>-D$ (so that the constant money supply is equal to $M *=D+F *>0$ ). The associated stationary equilibrium is given by $c_{i}(s)=\bar{c}_{i}, M_{i}(s)=M * \bar{c}_{i} / y$ for each type $i$ in each state $s$; the quantity limits $\left\{\bar{c}_{i}\right\}$ are defined by

$$
\eta_{i} u^{\prime}\left(\bar{c}_{i}\right)=\alpha>0
$$

for each $i$, and the requirement that (1.3) hold with equality; $\bar{M}_{i}=M * \bar{c}_{i} / y$ for each type;

$$
\begin{gathered}
\lambda=\frac{M *}{y}, \\
\nu=\frac{\delta(1) \alpha y}{M *}
\end{gathered}
$$

and the sequence $\left\{p_{s}\right\}$ is defined by (2.4), using (3.10a). The sequence $\left\{r_{s}\right\}$ is chosen so that $r_{1}=\beta^{-1}$, and

$$
r_{s} \geq \frac{\delta(s)}{\beta \delta(1)} \sum_{s^{\prime} \geq s} \pi_{g^{\prime}}
$$

for each $s>1$. The sequence $\{\rho(s)\}$ is then given by

$$
\rho(\bar{s})=r_{\bar{s}},
$$

and

$$
\rho(s)=\frac{r_{s}\left[\sum_{s^{\prime} \geq s} \pi_{s^{\prime}}\right]-r_{s+1}\left[\sum_{s^{\prime} \geq s+1} \pi_{s^{\prime}}\right]}{\pi(s)}
$$

for all $s<\bar{s}$. Substitution of these values into the equilibrium conditions listed at the end of section 2 allows one to verify that all conditions for a stationary equilibrium are satisfied.

Furthermore, any policy that achieves the first-best outcome in case (3.2) must be essentially of this kind. For it is only possible to have a common value of $c(s)$ in all states if aggregate expenditure $Y(s)$, and hence the money supply $M(s)$, is the same in all states. It is easily verified that all of conditions (3.10) must hold in any equilibrium that results in the first-best allocation. The monetary policy correspondence $\Gamma$ consistent with such an equilibrium must possess a vertical segment, for at least the range of values for $\rho(s)$ in which one finds all of the elements in the sequence defined by (3.10d)-(3.10e), and it is only this part of the correspondence that matters in equilibrium.

The conclusion that the first-best allocation can be attained, even in this case, depends upon assuming that direct control of the volume of lending (and of the money supply) is possible. In particular, if for any $s>1$,

$$
\frac{\delta(s)}{\delta(1)}\left[\sum_{s^{\prime} \geq 9} \pi_{s^{\prime}}\right]^{2}+\beta \sum_{s^{\prime} \leq s-1} \pi_{s^{\prime}}>1,
$$


there is a contradiction between (3.10c)-(3.10e) and the requirement that $\rho\left(s^{\prime}\right)>0$ for all $s^{\prime} \geq s$. This implies that no indirect policy is consistent with the first-best outcome, though a direct policy of the form (3.8) is.

Rather than develop further the question of what can be achieved by indirect policy in such a case, let us turn instead to taste variations of a form other than (3.2). In general, the first-best allocation cannot be achieved, even by a direct policy. And when it cannot be, it is not generally true that the best policy is of the form (3.8), even if complete control of the money supply is possible.

The second polar case, variation purely on the extensive margin, as described by (3.3), illustrates this in an especially sharp way. It is easily seen that the first-best is not attainable in this case, but the second-best allocation is, and so optimal policies are those that support this allocation. A policy that achieves it, and is therefore optimal, is a perfectly elastic supply of funds,

$$
\Gamma=\left\{(\rho, F) \mid r=r^{*}\right\},
$$

where the nominal interest rate $r^{*}$ is equal to $\beta^{-1}$. The associated stationary equilibrium is given by the second-best allocation defined above; borrowing plans according to which, for each type, $M_{i}(s)=0$ for all $s<s_{i}$, and $M_{i}(s)=\bar{M}_{i}$ for all $s \geq \underline{s}_{i}$; and quantity limits $\left\{\bar{c}_{i}\right\}$ defined by (3.7) and the requirement that (1.3) hold with equality, and $\left\{\bar{M}_{i}\right\}$ defined by

$$
\bar{M}_{i}=\nu^{-1} \eta_{i} \bar{c}_{i} u^{\prime}\left(\bar{c}_{i}\right)
$$

for some $\nu>0$ (independent of $i$ ). The series $\left\{p_{s}\right\}$ is given by (2.4), using the value $\lambda=\alpha \nu^{-1}$, while the series $\left\{r_{s}, \rho(s)\right\}$ are given by $r_{s}=\rho(s)=\beta^{-1}$ for each $s$. Again, substitution of these values into the equilibrium conditions at the end of section 2 allows one to verify that all conditions for a stationary equilibrium are satisfied.

Furthermore, any policy rule that achieves the second-best outcome in case (3.3) must be essentially of this kind. For given the second-best allocation, as characterized above, (2.23) requires that for each type $i$,

$$
\eta_{i} u^{\prime}\left(\bar{c}_{i}\right)=\beta \nu p_{\mathbf{s}_{i}} r_{\underline{s}_{i}} .
$$

Substitution of (2.4) into this and comparison with (3.7) then implies that $r_{\underline{g}_{i}}=$ $\alpha(\beta \nu \lambda)^{-1}$ for each $i$, and hence that $r_{s}$ is the same for all $s$. As $r_{1}$ must equal $\beta^{-1}$, this must be the common value for $r(s)$ (i.e., $\lambda \nu=\alpha$ ). so that $r_{s}=\beta^{-1}$ for each state such that $M(s)>M(s-1)$. Then $(2.8)$, together with the monotonicity of $\Gamma$, implies that $\rho(s)=\beta^{-1}$ for all $s$ as well. Thus $\Gamma$ must at least have a horizontal segment at height $\beta^{-1}$, which segment includes all of the points at which equilibria of the interbank market occur in any state. In particular, a constant-money-supply rule is clearly not optimal, as it is inconsistent with the second-best allocation in this case.

The elastic money supply (or interest-rate smoothing) rule (3.11) does increase the volatility of aggregate demand, in this case, as in traditional analyses like that 
of Poole (1970). And, for the same reasons as are stressed in Lucas and Woodford (1994), the resulting uncertainty about aggregate demand results in equilibrium supply commitments that cause some capacity to be left unused in some states. But this does not imply that such a policy leads to a less efficient allocation of resources. Idle capacity is inconsistent with attainment of the first-best allocation, but it may be consistent with attainment of the second-best, as it is in this case. Given the sequential service constraint, the idle capacity in low-demand states is a necessary consequence of the fact that an optimal fraction of capacity is committed to the supply of goods to types of buyers that consume only in high-demand states.

The efficiency result obtained in this polar case is closely related to Prescott's (1975) argument for the efficiency of an equilibrium with idle capacity. Prescott's model is one in which prices are fixed in advance for individual units of capacity, but these are not committed to the supply of goods to individual buyers. Yet the equilibrium in his model is formally analogous to the goods market equilibrium described here; the crucial difference is that as he assumes no cash-in-advance constraint on purchases, his buyers behave in the way that buyers do in the present model when facing a perfectly elastic supply of credit at a zero interest rate. However, in the present model, an elastic supply of credit at a positive interest rate results in the same allocation of resources as would a zero interest rate; equilibrium goods prices and borrowing are simply all rescaled by a certain positive factor. Thus the equilibrium allocation here in the case of an elastic supply of credit at the interest rate $r^{*}=\beta^{-1}$ is the same as in Prescott's model, which he shows to be efficient in the case of certain preferences that constitute a special case of (3.3).

The two polar cases illustrate in their pure form two alternative considerations with regard to optimal monetary policy, that will more typically each deserve some weight. On the one hand, insofar as demand uncertainty has to do with variation in the intensity of demand of all buyers (the intensive margin), interest rates rising with the volume of transactions will be desirable, as a way of inducing buyers to stabilize their level of purchases, reducing the degree to which producers of goods allow capacity to remain idle in low-demand states. But on the other hand, insofar as demand uncertainty has to do with variations in the number of buyers in the market (the extensive margin), interest-rate smoothing (and a money supply that varies with transactions demand) will be desirable, as a way of avoiding equilibrium goods and loan supply commitments that unduly benefit buyers with stable demand at the expense of those with volatile demand. Both considerations will deserve some weight, and the optimal funds supply schedule will in general be neither perfectly vertical nor perfectly horizontal, but upward-sloping.

This can be illustrated with a simple example of an intermediate case. Let there be two types and two states; with $\delta_{1}(2)>\delta_{1}(1)>0, \delta_{2}(2)>0, \delta_{2}(1)=0$. In this case as well, the second-best allocation of resources is attainable. The policy that achieves it can be shown to involve

$$
\rho(2)-\rho(1)=\frac{\pi_{2}}{\pi_{1}}\left(\frac{\delta_{1}(2)-\delta_{1}(1)}{\beta \delta_{1}(1)}\right),
$$




$$
\frac{M(2)-M(1)}{M(1)}=\frac{\bar{c}_{2}}{\pi_{2} \bar{c}_{1}} .
$$

Fixing the other parameters and letting $\delta_{1}(2)$ approach $\delta_{1}(1)$, the optimal degree of variation in the interbank funds rate goes to zero, while the optimal money supply remains higher in the high-demand state; in this limit, the optimal supply correspondence becomes arbitrarily flat. But if one lets $\delta_{1}(2)$ be made arbitrarily large, the optimal degree of variation in the money supply goes to zero (since $\bar{c}_{2} / \bar{c}_{1}$ approaches zero), while the optimal increase in the interbank funds rate in the high-demand state becomes arbitarily large; in this limit, the optimal supply correspondence becomes arbitrarily steep. Intermediate values of $\delta_{1}(2)$ can be found that will make optimal any arbitrarily chosen slope for the central bank's funds supply correspondence.

\section{Conclusion}

We have exhibited an equilibrium model with loan commitments, and seen how the terms of these differ according to borrower characteristics. A monetary policy that involves relatively little accommodation of the increased credit demand in high aggregate demand states results in a greater degree of discrimination among types of borrowers in the terms of equilibrium loan commitments, and hence a greater degree of constriction of the relative access of borrowers with more volatile demand for credit in high-demand states. We have seen that under certain circumstances the efficiency of resource allocation is reduced by such a policy (in the sense that average expected utility is lower), despite the fact that it stabilizes aggregate demand for goods, and as a result allows a higher average degree of utilization of existing productive capacity. This is because it may be desirable for monetary arrangements to allow borrowers with highly cyclical demand to be able to purchase goods in the states where they have particular need for such purchases, even at the expense of allowing some productive capacity to remain idle in low-demand states.

This result provides a rationale for interest-rate smoothing as a goal of monetary policy, even in the absence of stochastic disturbances to money demand of the kind considered by Poole (1970). Several qualifications to this conclusion, however, are in order. First of all, complete interest-rate smoothing has been shown to be optimal only in a certain polar case, in which the only sort of demand uncertainty relates to variation on the "extensive margin". More generally, some degree of increase in interest rates in high-demand states will be desirable, as illustrated by the example at the end of section 3 . Second, even in the polar case, the argument here does not really imply that nominal interest rates need be held forever constant. The efficiency gain demonstrated simply requires that the central bank commit itself to an elastic supply of funds at a given nominal interest rate during each period, which interest rate is fully predictable at the beginning of the period (in particular, at the time that loan commitments are negotiated). There is no necessity that this interest rate be the same in all periods; the latter feature of the optimal policy considered above results from our restriction of attention to stationary policies, in which the monetary 
policy correspondence $\Gamma$ is the same each period. Thus our model really provides a motive for ensuring short-run predictability of nominal interest rates, rather than a genuine interest rate peg. It thus provides a possible justification for what Goodfriend (1991) reports as the U.S. Federal Reserve's efforts to avoid "whipsawing the market", and for the widespread use of a short-term nominal interest rate as the instrument of monetary policy, without implying that nominal interest rates should not, for example, be eventually raised if inflation increases.

How far in advance does it matter that nominal interest rates be predictable? The answer provided by our model is, as far in advance as the time lag over which the terms of loan commitments are not adjusted to reflect new market conditions. It might be thought that, in practice, this should not be long, and that as a result little smoothing of interest rates is justified. But it should be noted that the model also implies that monetary tightening should not be effective as way of offsetting the effects of real disturbances to aggregate demand, nor needed in order to prevent such disturbances from affecting the degree of utilization of productive capacity, except insofar as the monetary tightening occurs before information about the shock and the monetary response to it can be incorporated into the terms upon which goods are offered for sale. Thus as long as the lags in the adjustment of loan commitments are as long as the lags in the adjustment of goods supply commitments (as assumed here), there is no scope for using monetary policy to moderate the effects of real demand disturbances upon capacity utilization, without its having the consequences for the allocation of credit among different types of borrowers that have been illustrated above. 


\section{REFERENCES}

Bernanke, B. and M. Gertler, 1995, Inside the black box: The credit channel of monetary policy transmission, Journal of Economic Perspectives, Fall, 27-48.

Carlton, D., 1991, The theory of allocation and its implications for marketing and industrial structure, NBER Working Paper no. 3786, July.

Clarida, R. and M. Gertler, 1995, How the Bundesbank conducts monetary policy, unpublished, Columbia University, October.

Diamond, P.A., 1994, On time (Cambridge University Press, Cambridge).

Diamond, D. and P. Dybvig, 1983, Bank runs, deposit insurance, and liquidity, Journal of Political Economy 91, 401-419..

Eden, B., 1994, The adjustment of prices to monetary shocks when trade is uncertain and sequential, Journal of Political Economy 102, 493-509.

Fuerst, T.S., 1992, Liquidity, loanable funds, and real activity, Journal of Monetary Economics 29, 3-24.

Goodfriend, M., 1991, Interest rates and the conduct of monetary policy, CarnegieRochester Conference Series 34, 7-30.

Lucas, R. E., Jr., 1972, Expectations and the neutrality of money, Journal of Economic Theory 4, 103-124.

- - - , 1990, Liquidity and interest rates, Journal of Economic Theory 50, 237-264.

- - - , and M. Woodford, 1994, Real effects of monetary shocks in an economy with sequential purchases, unpublished, University of Chicago, April.

Meltzer, A., 1995, A history of the Federal Reserve, Chapter Two: The development of central banking theory and practice, unpublished, Carnegie-Mellon University, November.

Miron, J., 1986, Financial panics, the seasonality of the interest rate, and the founding of the Fed, American Economic Review 76, 125-140.

Morgan, D.P., 1992, Bank loan commitments and the lending view of monetary policy, Research Working Paper no. 92-09, Federal Reserve Bank of Kansas City, December.

Poole, W., 1970, Optimal choice of monetary policy instruments in a simple stochastic macro model, Quarterly Journal of Economics 84, 197-216.

Prescott, E.C., 1975, Efficiency of the natural rate, Journal of Political Economy 83, 1229-1236.

Rockafellar, R.T., 1970, Convex analysis (Princeton University Press, Princeton). Taylor, J.B., 1993, Discretion versus policy rules in practice, Carnegie-Rochester Conference Series 39, 195-214.

Wojnilower, A.M., 1980, The central role of credit crunches in recent financial history, Brookings Papers on Economic Activity 1980:2, 277-326. 